ISSN 1991-8631

Original Paper

http://indexmedicus.afro.who.int

\title{
Anatomical distribution and biochemical composition of urolithiasis in Kano, northern Nigeria
}

\author{
M.A. EMOKPAE ${ }^{1,2 *}$ and A.A. GADZAMA ${ }^{2,3}$ \\ ${ }^{I}$ Department of Chemical Pathology, Aminu Kano Teaching Hospital, Kano, Nigeria. \\ ${ }^{2}$ Department of Medical Laboratory Science, School of Basic Medical Sciences, College of Medical Sciences, \\ University of Benin, Benin City, Nigeria. \\ ${ }^{3}$ Department of Chemical Pathology, University of Maiduguri Teaching Hospital, Maiduguri, Nigeria. \\ *Corresponding author, E-mail: biodunemokpae@yahoo.com
}

\begin{abstract}
Urinary lithiasis disorder is one of the oldest disorders known to man yet the anatomic locations of urolithiasis and the chemical compositions vary from one geographic location to another. This study therefore analyzed the anatomic location of urolithiasis and their chemical composition in a sudano-sahelian tropical region. All Urolithiasis extracted from or passed by patients attending Murtala Mohammed Specialist Hospital, Abubakar Imam Urology centre and Aminu Kano Teaching Hospital within the period of four years (20002003) were collected, their anatomic locations documented, and analyzed for chemical composition by chemical method. Urolithiasis occur in males six fold more than in females. On the whole the lower urinary stones consisted of $55.7 \%$, while the upper urinary stone was $44.3 \%$ of the total urolithiasis extracted ( $>0.05)$. The most frequent anatomic site for all urolithiasis is the urinary bladder $(38.6 \%)$ followed by ureteric lithiasis (21.4\%). Renal stone is more frequent than stones excreted in the urine, $17.1 \%$ and $16 \%$ respectively. Both urethral and gall gladder lithiasis presented with equal frequency of $8 \%$. Calcium was present in $86.2 \%$ of the stones analyzed. Urate and magnesium were not components of all the urethral lithiasis analyzed. Urolithiasis was rare over the age of 65years. Frequency of composite analytes in the stones is presented. The lower urinary calculi were commonest in this centre than the upper urinary calculi and the chemical composition of urological calculi is similar to those reported in other parts of Nigeria.
\end{abstract}

(C) 2012 International Formulae Group. All rights reserved.

Keywords: Urinary lithiasis, biochemical composition and distribution; calculi and stone formations.

\section{INTRODUCTION}

Urinary stones are polycrystalline aggregates consisting of varying amount of crystals. Urinary stone disorder is one of the oldest disorders known to man, yet the anatomic locations of the urolithiasis and its chemical compositions vary from one geographical location to another. Urolithiasis is caused by a variety of conditions which include metabolic and inherited disorders, anatomical defects with or without chronic urinary infections (Johri et al., 2010). It has been reported that about $40 \%$ of first-time stone formers are likely to form a second stone within 3 years of the first episode if no prophylactic measures are not taken to prevent 
its occurrence or if the cause of the first episode is treated (Arrabal et al., 2006; Spivacow et al., 2006; Johri et al., 2010). The human urine when supersaturated with ions and molecules which have the ability to crystallize as clinical crystaluria has a potential for urinary stone formation. The prevalence of urolithiasis has been on the increase in the past decades in both developed and developing countries (Ngo and Assimos, 2007). In Nigeria, earlier reports showed low prevalence until recent studies indicated a rising incidence of urolithiasis (Adetayo et al.,2004; Mshelia et al., 2005). Accurate analysis of urinary stone components is fundamental for studying the etiology of urolithiasis and it is essential for treatment and prevention (Seok et al., 2007). In addition, because of increasing incidence of renal diseases (Quaader et al., 2006), particularly those arising from complications of urolithiasis underscore the need to understand anatomical location and chemical composition of urolithiasis. This study therefore analyzed the chemical compositions and anatomic locations of urolithiasis in Kano, northern Nigeria.

\section{MATERIALS AND METHODS}

One hundred and forty urolithiasis patients from Murtala Mohammed specialist Hospital, Abubakar Imam Urology centre and Aminu Kano Teaching Hospital Kano with records of urolithiasis locations were recruited into the study over four years period (20002003). All urolithiasis extracted from or passed were collected, washed with deionized water and dried at room temperature. Large urolithiasis was sawed into smaller parts and dried. Dried urolithiasis was weighed; then completely crushed in a mortar and its chemical composition was determined using chemical methods of Ermalinda and Fiereck (Henderson.1995). All statistical tests were 2tailed analysis computed by Graphpad insta version 3 and p-value less than 0.05 was considered statistically significant.

\section{RESULTS}

We observed a six fold urolithiasis occurring in males than in females. On the whole, the lower urolithiasis consisted of $55.7 \%$, while the upper urolithiasis were $44.3 \%$ of the total urolithiasis extracted $(\mathrm{p}>0.05)$. The most frequent anatomic site for all urolithiasis is the urinary bladder $38.6 \%$ followed by ureteric lithiasis $(21.4 \%)$ (Table 1 and Figure 1). Renal lithiasis was more frequent than lithiases that were spontaneously excreted in the urine, $17.1 \%$ and $16 \%$ respectively. Urethral lithiasis presented with a frequency of $8 \%$ like gall gladder stone. Calcium was present in $86.2 \%$ of stones from renal, ureteric, urinary and gall bladder stones. Urate and magnesium were not found in urethral stones. Urological stone formation was rare over the age of 65years. The chemical compositions of all the urinary bladder stones analyzed were calcium $(30.5 \%)$, phosphate $(29.3 \%)$, oxalate $(18.3 \%)$, urate $(14.6 \%)$ and magnesium $(7.3 \%)$ (Figure 2). Among all the urethral stones, the compositions were calcium $(42.9 \%)$, oxalate $(42.9 \%)$, and phosphate (14.2\%) (Figure 3). Stones passed out spontaneously composed of calcium (32\%), oxalate $(16 \%)$, phosphate $(32 \%)$, urate $(16 \%)$, and magnesium $(4 \%)$ (Figure 4). Calcium was found in $31.2 \%$ of renal stones, oxalate $(28.8 \%)$, phosphate $(23.7 \%)$, urate $(13.2 \%)$ and magnesium (2.6\%) of all renal lithiasis (Figure 5). The percentage compositions of ureteric stones were calcium $(27.8 \%)$, oxalate $(18.5 \%)$, phosphate $(25.9 \%)$, urate $(14.8 \%)$ and magnesium (13.0\%) (Figure 6). The compositions of the gall bladder stones were calcium $(25 \%)$, bilirubin $(25 \%)$, cholesterol $(25 \%)$ and urate $(25 \%)$. The frequency of occurrence of calcium in all stones both urological and gall bladder is $86.2 \%$, phosphate was found in $63.7 \%$ of the stones, oxalate in $56.5 \%$, urate in $39.9 \%$, magnesium in $17.0 \%$, bilirubin in $8.3 \%$ and cholesterol found in $8.3 \%$ of all the stones. Figure 8 shows the different chemical composition of stones in the different anatomical sites. 
Table 1: Anatomical sites and chemical compositions of urolithiasis.

\begin{tabular}{lcccccccc}
\hline $\begin{array}{l}\text { Urolithiasis } \\
\text { site }\end{array}$ & No (\%) & calcium & oxalate & phospate & urate & $\mathbf{M g}^{2+}$ & Bilirubin & Chol \\
\hline Bladder & $54(38.6)$ & 92.6 & 55.6 & 88.9 & 44.4 & 22.2 & - & - \\
Urethral & $8(5.7)$ & 75 & 75 & 25 & - & - & - & - \\
Urinary & $16(11.4)$ & 100 & 50 & 100 & 50 & 25 & - & - \\
Renal & $24(17.1)$ & 100 & 91.7 & 75 & 41.7 & 8.3 & - & - \\
Ureteric & $30(21.4)$ & 100 & 66.7 & 93.3 & 53.3 & 46.7 & - & - \\
$\begin{array}{l}\text { Gall } \\
\text { bladder }\end{array}$ & $8(5.7)$ & 50 & - & - & 50 & - & 50 & 50 \\
$\begin{array}{l}\text { Mean \% } \\
\text { composition }\end{array}$ & $140(100)$ & 86.2 & 56.5 & 63.7 & 39.9 & 17.0 & 8.3 & 8.3 \\
\hline
\end{tabular}

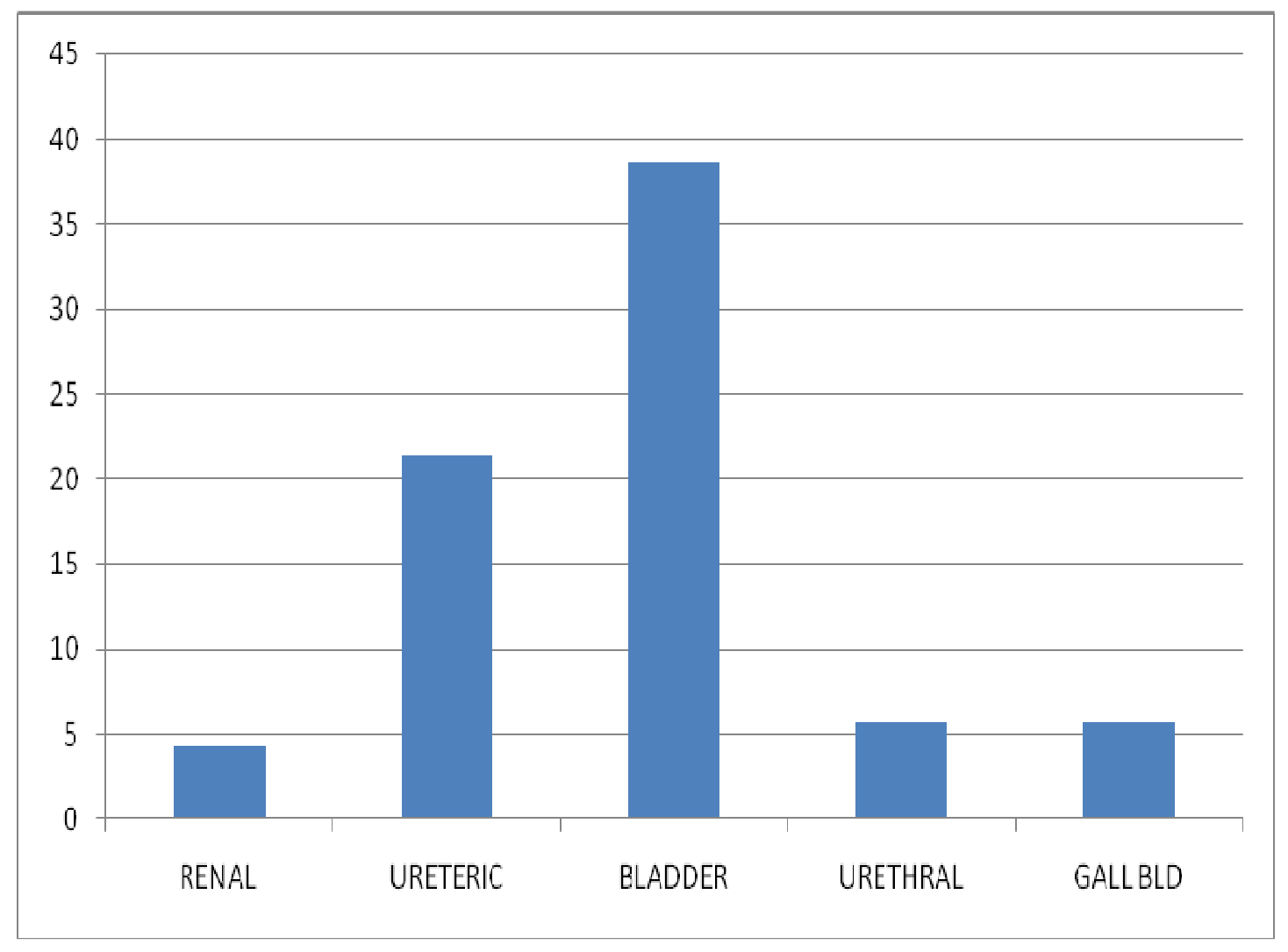

Figure 1: Anatomical distrubution of lithiasis in Kano, Nigeria. 


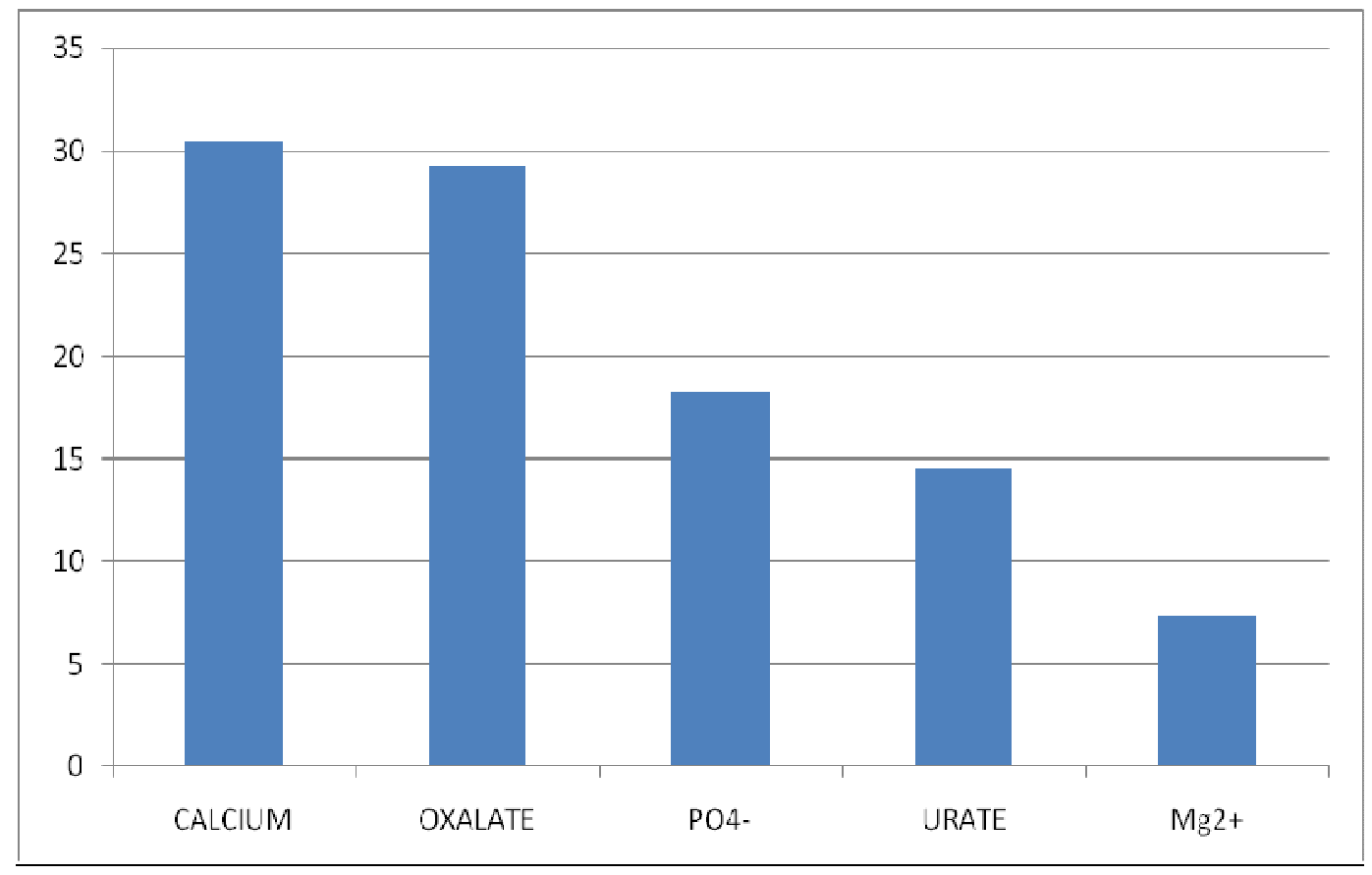

Figure 2: Percentage composition of bladder lithiasis.

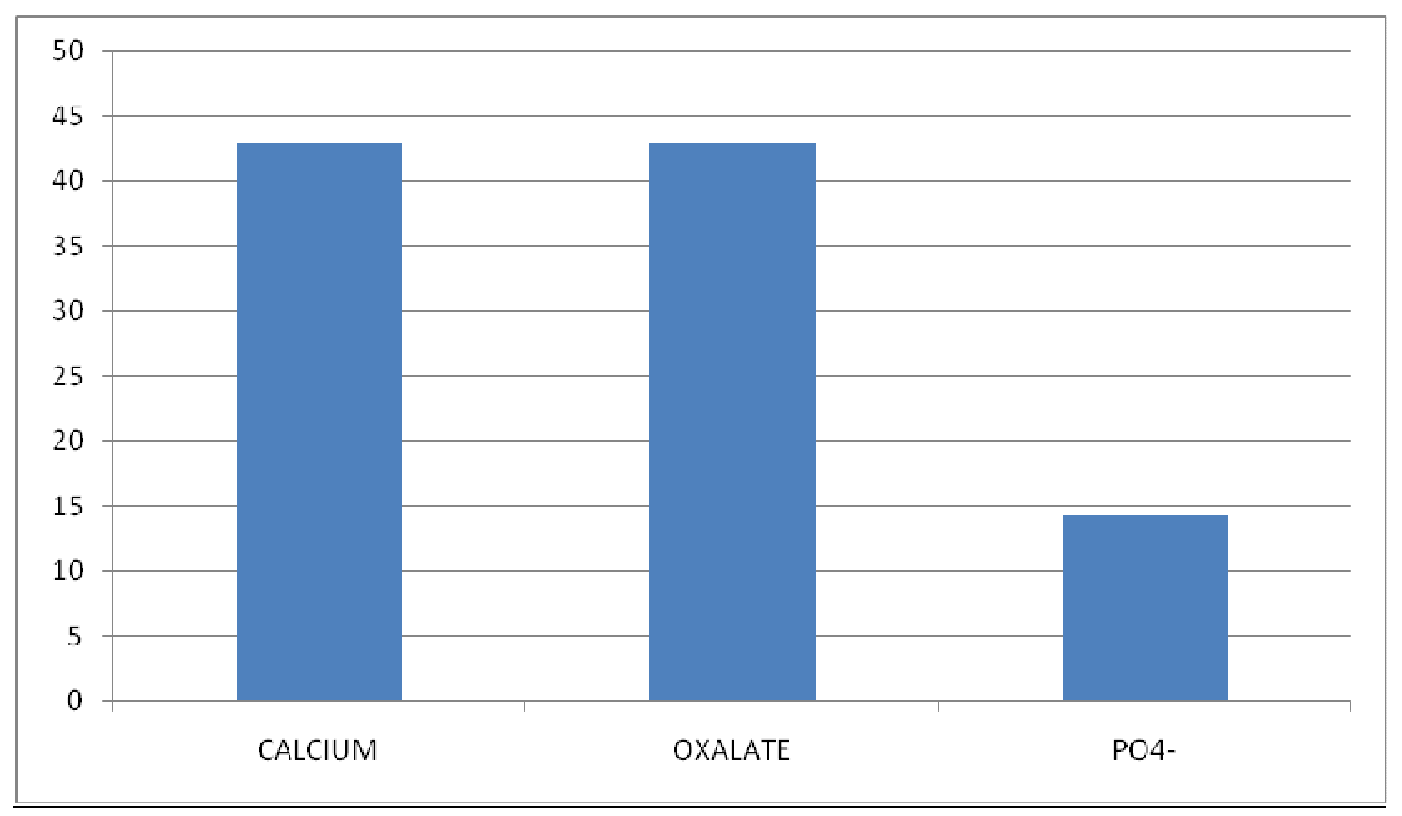

Figure 3: Percentage composition of urethral lithiasis. 
M.A EMOKPAE and A.A GADZAMA / Int. J. Biol. Chem. Sci. 6(3): 1158-1166, 2012

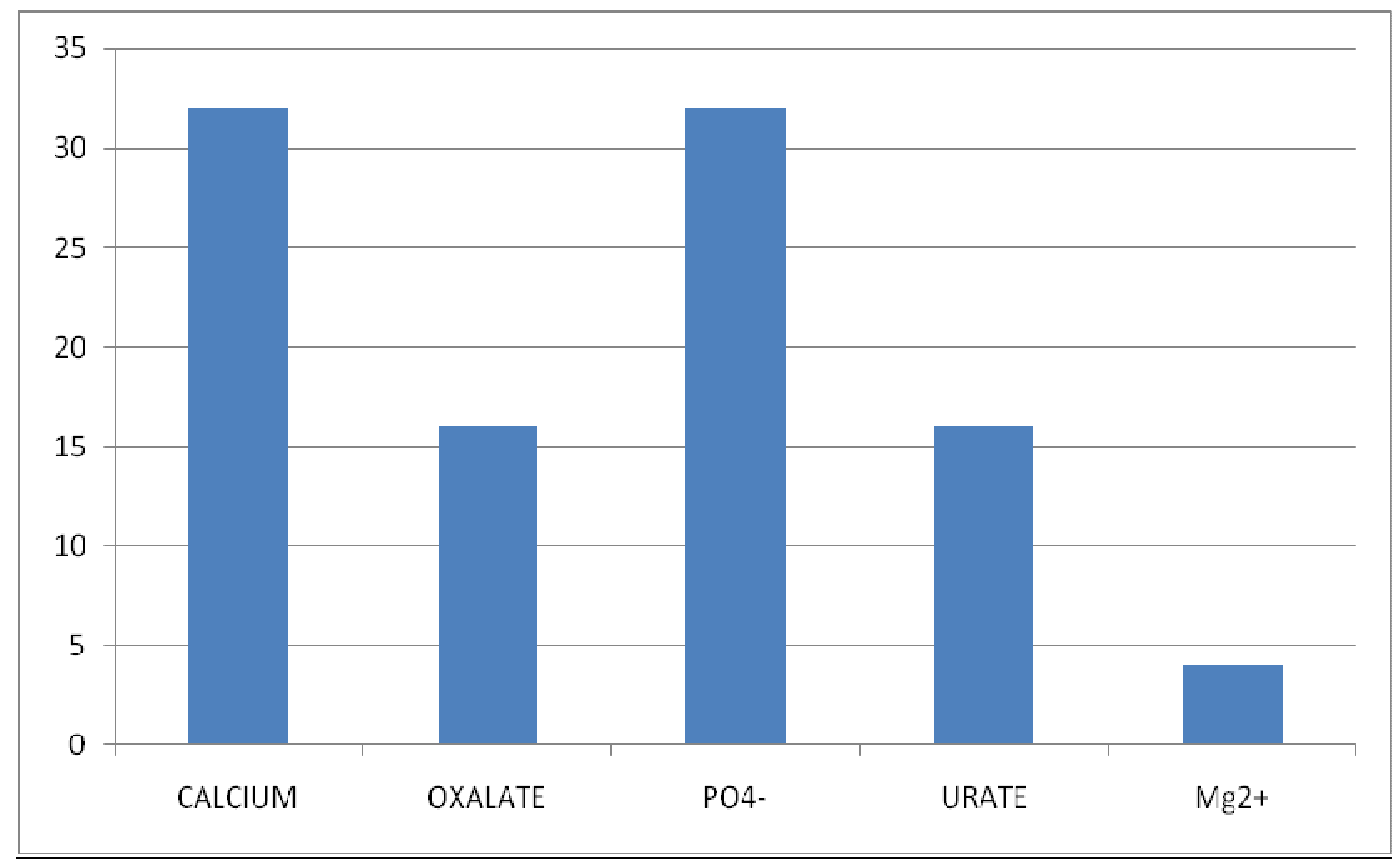

Figure 4: Percentage composition of urinary lithiasis.

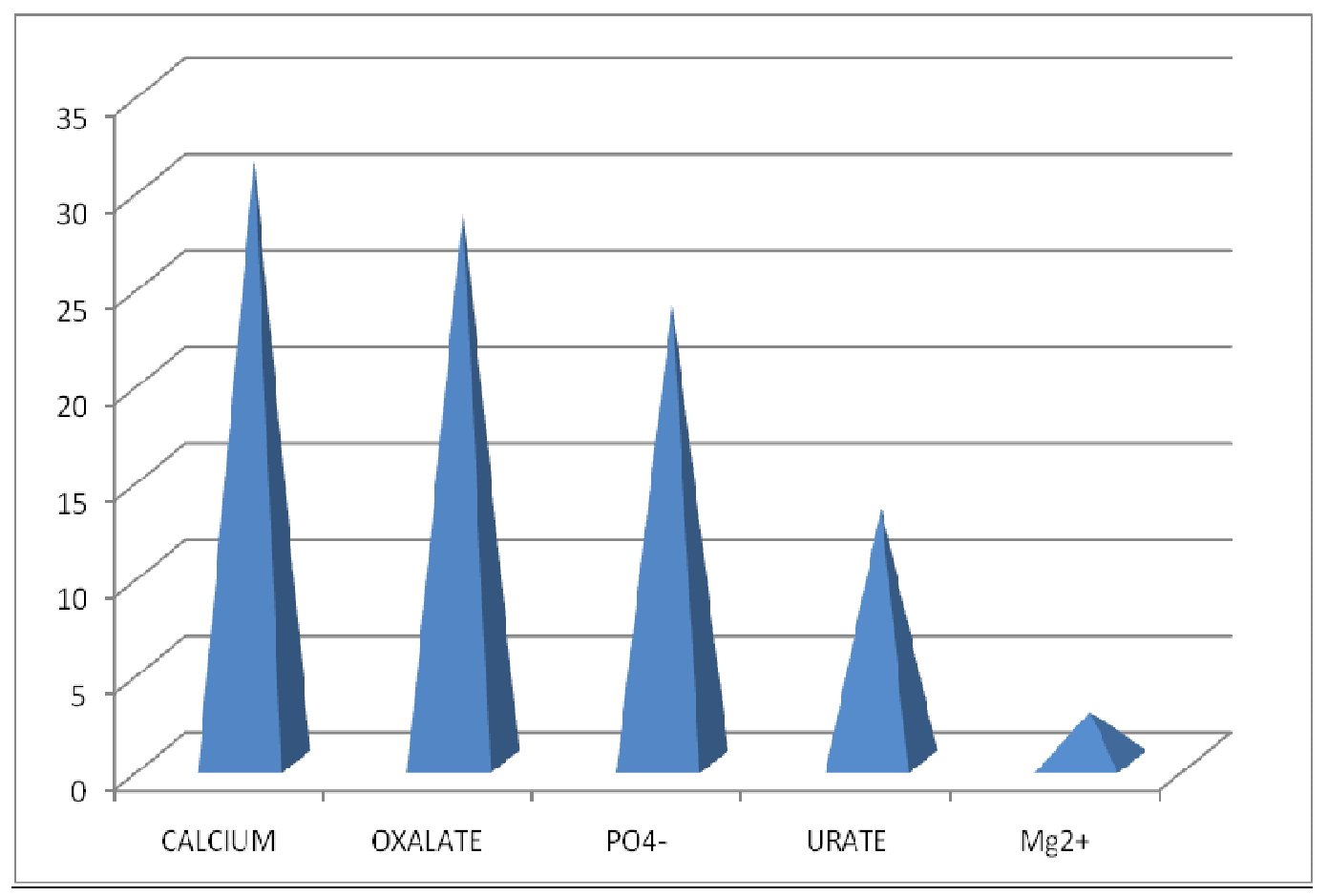

Figure 5: Percentage composition of renal lithiasis. 


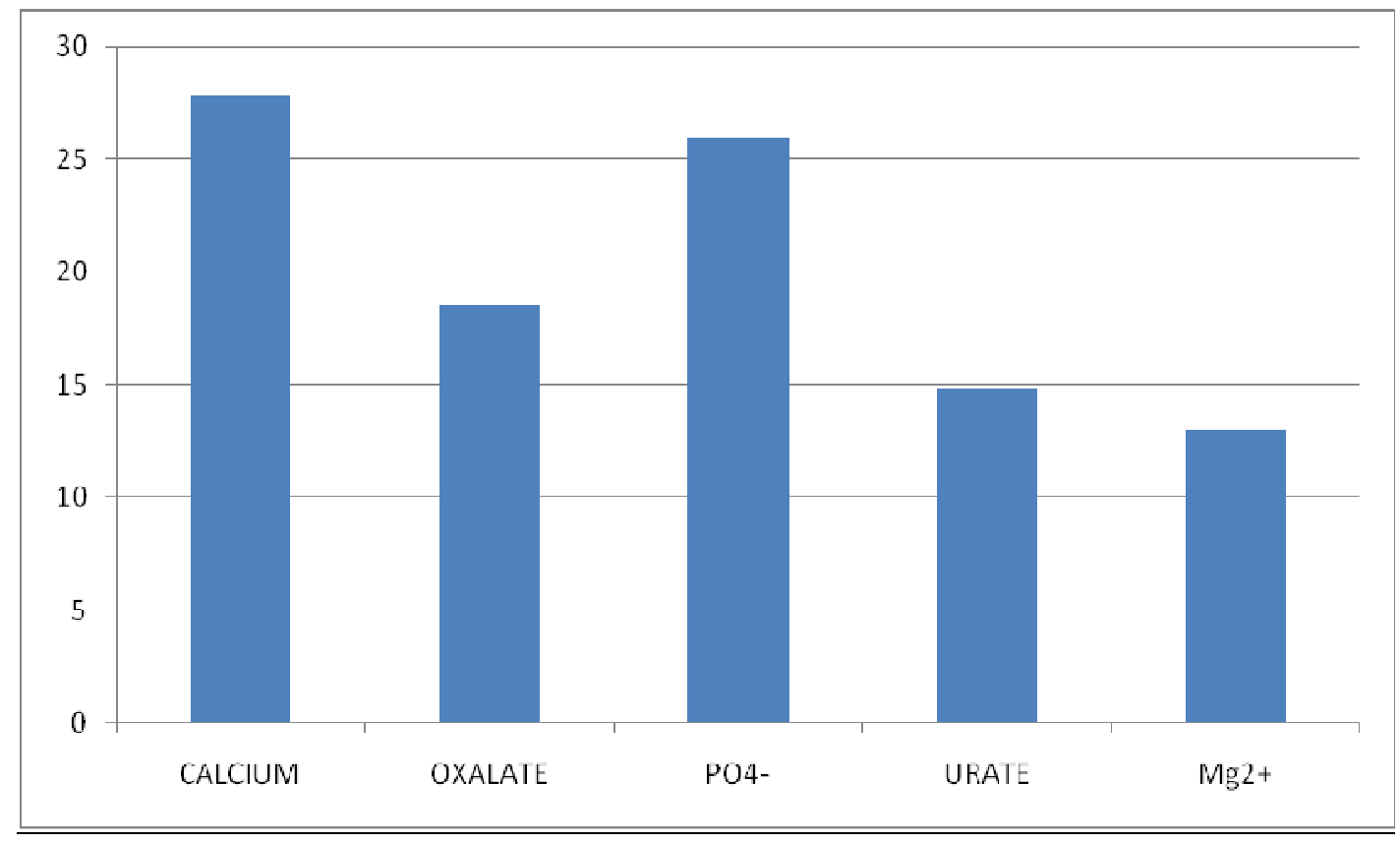

Figure 6: Percentage composition of ureteric lithiasis.

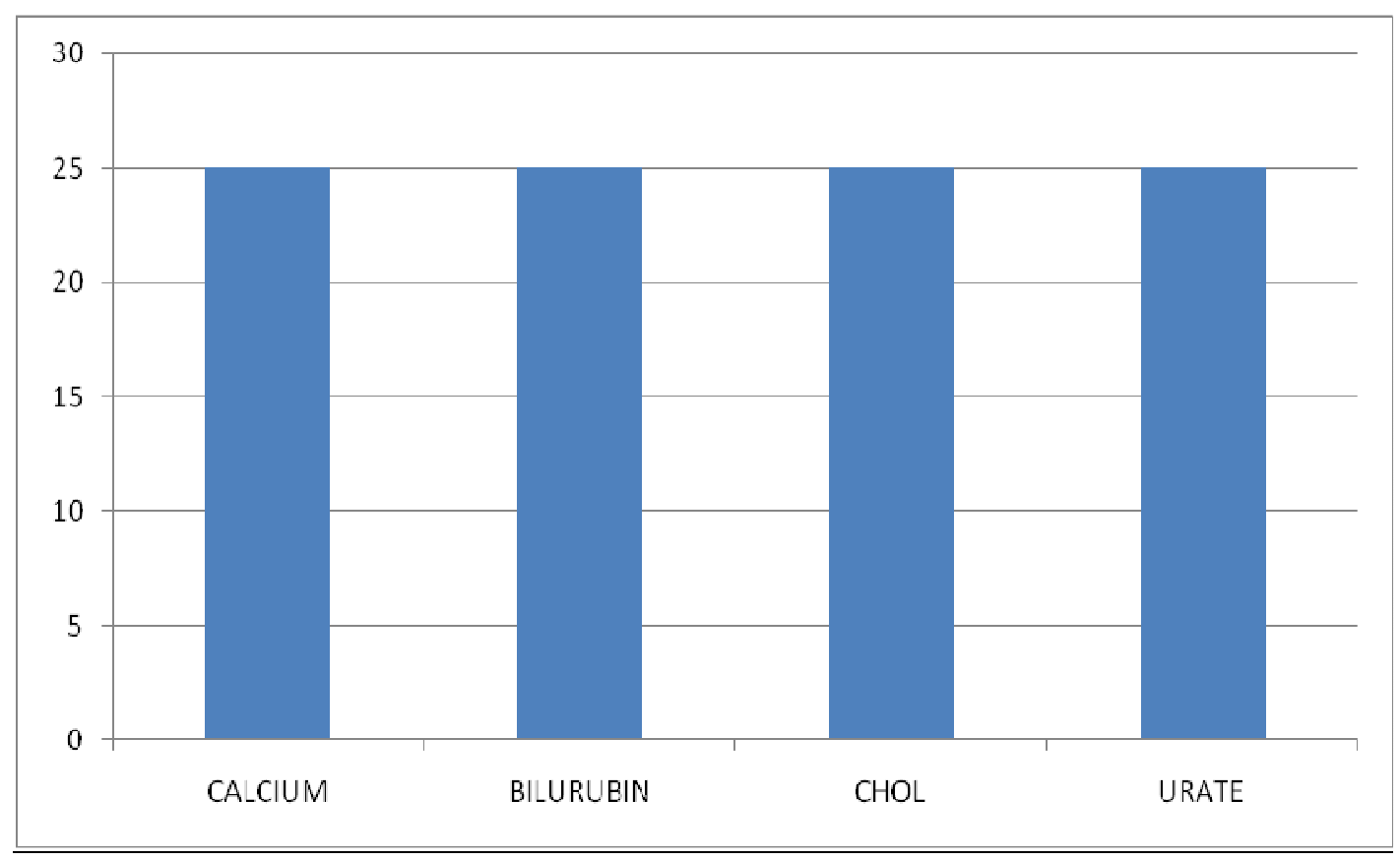

Figure 7: Percentage composition of gall bladder lithiasis. 


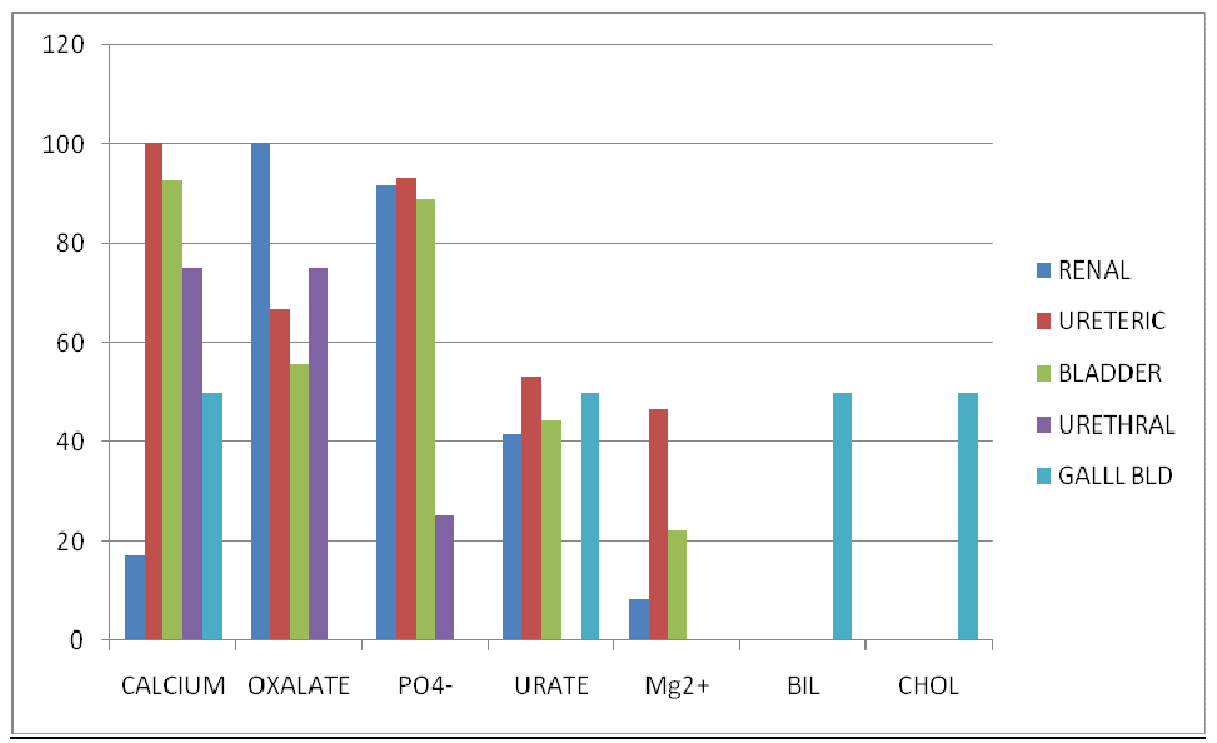

Figure 8: Presence of analytes amongst stones in different anatomical sites.

\section{DISCUSSION}

The most frequent anatomic site of lithiasis in this centre is urinary bladder followed by ureteric, renal, urinary, urethral and gall bladder. This finding is similar to others elsewhere in Africa (Ahmed and Saeed, 2008: Alemu, 2008) but different from those from other continents of the world (Seok et al., 2007; Johri et al., 2010). It is important to analyze stone composition because certain types of stones once identified and appropriate treatment given may prevent reoccurrence. Our finding of preponderance of male with urolithiasis is similar to other studies (Mshelia et al., 2005; Mandel and Mandel, 2007; Alemu, 2008). This can be explained in part by the strenuous work men do in northern Nigeria. Strenuous work demands three times more fluid to maintain fluid balance; again hot environment requires twice the volume of fluid than climate environment. Both predisposing factors for urolithiasis are common in northern Nigeria particularly in the harsh dry months of the year. A possible explanation for the male preponderance in this environment is stress; known predisposing factor for urolithiasis is commoner in male than females in this environment. Albumin's role in promoting urolithiasis is well elucidated (Endres and Rude, 2006) and could in part explain the male preponderance for urolithiasis in this environment since male has higher albumin than females (Gadzama et al., 2006).The higher urolithiasis recurrence rate in male may increase preponderance of urolithiasis in male (Kodama and Ohno,1989). The incidence rate of urolithiasis in male to female was 6:1 which was higher than 4.93:1 reported in Iran (Mohammad et al., 2011). Although the female sex is a predisposing factor for urolithiasis formation, this role has been overcome by more favourable urolithiasis predisposing and promoting factors associated with males in Nigeria and other African countries (Alemu, 2008). Therefore, female sex has not played any observable role in predisposing females to urolithiasis in Nigeria. The role of drinking water to stone formation is controversial and was not considered in this study. Studies have shown that Calcium quantity of tap water may cause hypercalciuria with concomitant hypooxaluria (Caudarella et al., 1998; Coen et al., 2001). It was also suggested that drinking of soft water as against hard water may be associated with low risk of calcium stone 
formation (Bellizi et al., 1999). However, Mohammad et al. (2011) recently observed that biochemical urinary stone composition is independent of the type of drinking water (high or low water hardness) available in an environment.

Anatomical locations of urolithiasis in this study are mainly similar to findings elsewhere in Africa (Mshelia et al., 2005; Alemu, 2008). The slight difference in the anatomical location can be explained by the inclusion of urological stones passed by the patients which other studies did not put into consideration. Our finding of stones spontaneously passed by patients in urine is consistent with that of Ahmed and Saeed, (2008), that urethral stones are easily and safely movable in the urethra by urinary catheter. Changing socioeconomic conditions have generated changes in the incidence and type of urolithiasis in terms of site and chemical composition of the calculi (Hossaini et al., 2003). The prevalence of urolithiasis varies considerably on account of environmental factor, dietary intake, climatic condition and life style (Trinchieri, 1996). Our finding of predominant lower urinary urolithiasis is similar to the findings in Ethiopia (Alemu, 2008), and in other developing countries (Kodama and Ohno, 1989) as against findings in developed countries where upper urological urolithiasis dominate (Kodama and Ohno, 1989; Peres et al., 2011). Contrast between the developed and the developing countries with regards to positioning of urolithiasis is said to result from socioeconomic reasons as the occurrence of urolithiasis in the nineteenth century Europe is quite similar to urolithiasis of the twentieth century Asia (Henderson,1995; Trinchieri,1996; Djelloul et al., 2006). Strenuous work, known to cause dehydration is done by men in the developing countries unlike the rich developed world that uses technology and eliminates sustained severe dehydration. In the absence of replacement of such urolithiasis predisposing tasks in the developing countries, there is the urgent need to educate the employers of labour to provide adequate fluid and encourage increased fluid intake by their staff at risk.

\section{Conclusion}

Lower urinary calculi are predominant in this centre and the female sex has no role in predisposing Nigerians to stone formation. There is need for public health education in order to reduce the occurrence of calculi formation.

\section{REFERENCES}

Adetayo FO, Saanu OO, Osegbe DN. 2004. Chemical composition of urinary calculi in Nigerians. Nig. Q. J. Hosp. Med., 14(2): 143-146.

Ahmed A, Saeed NM. 2008. Experience with the management of urethral stones presenting with urinary retention at Gusau. Niger J. Clin. Pract., 11(4): 309311.

Alemu MH. 2008. Pattern of urinary stone diseases in Makelele, Ethiopia. Ethiop. Med. J., 46(3): 237-241.

Arrabal MM, Fernandez RA, Arrabal PMA, Ruiz GMJ, Zuluaga GA. 2006. Study of the physical-chemical factors in patients with renal lithiasis. Arch. Esp. Urol., 59(6): 583-594.

Bezilli V, De Nicola L, Minutolo R, Russo D, Cianciaruso B, Andreucci M, Conte G, Andreucci VE. 1999. Effects of water hardness on urinary risk factors for kidney stones in patients with idiopathic nephrolithiasis. Nephron, 81(1): 66-70.

Caudarella R, Rizzoli E, Buffa A, Bottura A,Stefoni S. 1998. Comparative study of the influence of 3 types of mineral water in patients with idiopathic calcium lithiasis. J. Urol., 159(3): 658-663.

Coen G, Sardella D, Barbera G, Ferrannini M, Comegna C, Ferazzoli F, Dinnella A, D'Anello E, Simeoni P. 2001. Urinary composition and lithogenic risk in normal subjects following oligo mineral versus bicarbonate-alkaline high calcium mineral water intake. Urol Int., 67(1): 49-53. 
Endres DB, Rude RK. 2006. Mineral and bone metabolism. In Tietz Textbook of Clinical Chemistry and Molecular Diagnostics $\left(5^{\text {th }}\right.$ edn). Burtis carl A, Ashwood Edward R (eds). WB Sunders: Philadelphia; 1900-1965.

Djelloul Z, Djelloul A, Bedjaoui A, KaidOmar Z, Attar A, Daudon M, Addou A. 2006. Urinary urolithiasis in western Algeria: study of the composition of 1,354 urinary urolithiasis in relation to their anatomical site and the age and gender of the patients. Prog. Urol., 16(3): 328-335.

Gadzama AA, Emokpae A,Akande AA. 2006. Stratification enhances sensitivity of reference values for serum urea. Tropical. J. Health Sci., 13(12): 24-26.

Henderson MJ.1995. Urolithiasis analysis is not useful in the routine investigation of renal urolithiasis disease. Ann. Clin. Biochem., 32: 109-111.

Hossain RZ, Ogawa Y, Hokama S, Morozunu M, Hatano T. 2003. Urolithiasis in Okinawa, Japan: a relative high prevalence of uric acid urolithiasis. Int. J. Urol., 10(8): 411-415.

Jing Z, Guo Zeng W, Ning J, Jia Wei, Yan G, Fang Y. 2010. Analysis of urinary calculi composition by infra red spectroscopy: a prospective study of 625 patients in eastern China. Urol. Res., 38(2): 111-115.

Johri N, Cooper B, Robertson W, Choong S, Rickards D, Unwin R. 2010. An-update and practical guide to renal stone management. Nephron Clin. Pract., 16(3): 159-171.

Kodama H, Ohno Y. 1989. Descriptive epidemiology of urolithiasis. Hinyokika Kiyo, 35(6): 923-934.

Mandel I, Mandel N. 2007. Structure and compositional analysis of kidney urolithiasis. In Current Clinical Urology, Urinary Urolithiasis Disease: A Practical Guide to Medical and Surgical Management, Stoller ML, Meng MV (eds). Humana Press Inc.: Totona, NJ; 8190.

Mohammad KM, Hossein S, Seyed MAJ. 2011. Evaluation of biochemical urinary stone composition and its relationship with tap water hardness in Qom province, central Iran. Int. J. Nephrol. Renovasc. Dis., 4: 145-148.

Mshelia DS, Gali BM, Naaya UH, Habu SA. 2005. Chemical composition of urinary calculi in Maiduguri, Nigeria. Afr. J. Med. Med. Sci., 34(2): 185-188.

Peres LA, Langer SS, Schmidt RC, Nacke RA, Francescon PV, Almeida RC, Coimbra RM, Ribas TM, Barros TD, Matsuo T. 2011. Nephrolithiasis in pediatric patients:metabolic and anatomical investigation. J. Bras Nefro., 33(1): 50-54.

Qaader DS, Yousif SY, Mahdi LK. 2006. Prevalence and etiology of urinary stress in hospitalized patients in Baghdad. Eastern Mediterranean Health J., 12(6): 853-861.

Seok JY, Eun SY, Yoon KP. 2007. Analysis of urinary stone components during the last two decades. Korean J. Urol., 48(12): 1285-1288.

Spivacow FR, Del Valle EE, Zancheta JR. 2006. Renal lithiasis, biochemical changes in the follow-up. Medicina, 66(3): 201-205.

Tin CN, Dean GA. 2007. Uric acid nephrolithiasis: recent progress and future directions. Rev Urol., 9(1): 17-27.

Trinchieri A. 1996. Epidemiology of urolithiasis. Arch. Ita. Urol. Androl., 68(4): 203-249. 